Association for Information Systems

AIS Electronic Library (AISeL)

\title{
Requirements for Augmented Reality Solutions for Safety-Critical Services - The Case of Water Depth Management in a Maritime Logistics Hub
}

\author{
Anna Osterbrink \\ Technische Universität Dortmund \\ Julia Bräker \\ Universität Hamburg \\ Martin Semmann \\ Universität Hamburg \\ Manuel Wiesche \\ Technische Universität Dortmund
}

Follow this and additional works at: https://aisel.aisnet.org/wi2021

Osterbrink, Anna; Bräker, Julia; Semmann, Martin; and Wiesche, Manuel, "Requirements for Augmented Reality Solutions for Safety-Critical Services - The Case of Water Depth Management in a Maritime Logistics Hub" (2021). Wirtschaftsinformatik 2021 Proceedings. 4.

https://aisel.aisnet.org/wi2021/TDigitalServices/Track07/4

This material is brought to you by the Wirtschaftsinformatik at AIS Electronic Library (AISeL). It has been accepted for inclusion in Wirtschaftsinformatik 2021 Proceedings by an authorized administrator of AIS Electronic Library (AISeL). For more information, please contact elibrary@aisnet.org. 


\title{
Requirements for Augmented Reality Solutions for Safety-Critical Services - The Case of Water Depth Management in a Maritime Logistics Hub
}

\author{
Anna Osterbrink ${ }^{1}$, Julia Bräker², Martin Semmann², and Manuel Wiesche ${ }^{1}$ \\ ${ }^{1}$ TU Dortmund University, Department of Business and Economics, Dortmund, Germany \\ \{anna.osterbrink, manuel.wiesche\}@ tu-dortmund.de \\ ${ }^{2}$ University of Hamburg, Department of Informatics, Hamburg, Germany \\ \{julia.braeker, martin.semmann\}@uni-hamburg.de
}

\begin{abstract}
Augmented reality (AR) is widely acknowledged to be beneficial for services that have exceptionally high requirements regarding knowledge and simultaneous tasks to be performed and are safety-critical. In such services, AR enables to augment service provision by delivering seamless integration of information in the field of view while enabling hands-free usage in the case of head-mounted displays. This study explores the user-centered requirements for AR solutions in the operations of a large European maritime logistics hub. Specifically, it deals with the process of soil sounding. Based on eleven thinkaloud sessions during service delivery, two expert interviews, and two expert workshops, we derived five core requirements for AR in soil sounding. Thus, we present the first study on the applicability and feasibility of AR in the maritime industry and identify requirements that impact further research on AR use in safety-critical environments.
\end{abstract}

Keywords: Mixed Reality, Service Engineering, Requirements, Think Aloud, Case Study

\section{Introduction}

In various industries, new technologies are becoming increasingly important in the development and improvement of services, and the use of these technologies has gained attention both in service research and in practice $[1,2]$. When using new technologies, the IT resources either complement or improve the effects of non-IT resources on the performance of a process or substitute them [3]. Well-known examples of services that were improved by technology are e-tickets in the airline or event business, electronic check-in and check-out systems in hotels, and electronic money transfer in financial services, etc. $[4,5]$.

As a result, the character of information technology has changed to the extent that it has become the focus of new product and service ideas due to technological developments both in hardware and software [6]. An example of this is the use of augmented reality (AR) head-mounted displays (HMD), through which current 
challenges, for example, in technical customer services, can be overcome [7]. With the help of HMDs, services can be restructured by enabling information to be displayed directly into the user's field of view under hands-free navigation without media breaks and limited mobility [8]. As a result, HMDs have a high potential to support [9] and improve [10] services such as health care [11], technical customer service [8], and logistics services [12, 13].

While previous studies have largely focused on services in which one task is performed, it is not well understood how AR can support services where two separate tasks are frequently switched. This is the situation in our use case of water depth management where skippers in the service provision of soil sounding simultaneously have to navigate their vessels and measure water depth with high accuracy. Since mistakes or inaccuracies in the performance of the two tasks of the skipper can have serious consequences both directly and indirectly, the use case is a safety-critical service, which can generally be characterized by the fact that a "failure might endanger human life, lead to substantial economic loss, or cause extensive environmental change" [14, p. 547]. Especially, for this reason, effective support and improvement of the process of soil sounding are very important as the resulting information is crucial for vessels to navigate harbor areas. Consequently, soil sounding is a key service to ensure safety for all actors that use the harbor infrastructure as this infrastructure is partially dynamic due to tides and currents. An additive complicating factor for an AR application on a vessel is that, in contrast to the already difficult implementation of AR for cycling or driving a car, there is an additional dimension of motion, namely that of the ground, i.e., the water on which the vessel is moving. Against this background, our research is guided by the questions (RQ1) How amenable is the service process of soil sounding to be supported by $A R$ ? and (RQ2) What are the requirements for $A R$ solutions to improve the service process of soil sounding?

To answer the research questions, the paper is structured as follows: First, we give an overview of the application of AR solutions in different service processes, distinguishing between those with a static setting and those where the environmental setting adapts to the user's motion, such as when driving a car. In section 3, we introduce the methodology, where we conducted a case study with workshop data, expert interviews, and process tracing using video observations and verbal protocols in the form of think-aloud sessions. In section 4 , we present the use case of water depth measurement and analyze it firstly with regard to its augmentability (RQ1). In the second part of the analysis, we use the conducted think-aloud sessions to derive the user-centered requirements for an AR solution for the service process of soil sounding (RQ2). The results and their limitations are discussed in section 6, and in section 7, we summarize the main findings and give an outlook on future research issues.

\section{Related Work}

Innovations in the field of service continue to emerge, with many of the innovations today being digital by integrating resources throughout service systems [15]. In order to apply service innovations and related innovative technologies that can be used to 
support services, it is important to understand the innovations within the service for which they are to be used, their potential, and the requirements involved $[16,17]$.

One technology with a very high potential for service innovation is AR. This technology can be used in many different environments that can be distinguished by the degree of dynamics. Environments with little dynamics - here called static environments - can be characterized by the fact that the user's environment does not change because the user does not move in public but is in a limited environment like a room in which objects like machines have a fixed, static place. In those scenarios, there are already insights on applications of AR, such as the design and prototyping of a seethrough HMD, which was carried out in the aircraft manufacturing industry to reduce costs and increase efficiency [18]. Increased efficiency was also observed for the use of AR-applied devices in the context of maintenance and repair [19, 20]. In engineering, AR welding guns with cameras to track the exact stud locations were used to support engineering processes [21]. Another AR application that was investigated is the use of smart glasses to support the runtime modeling of services, allowing the process to be documented on-site by the service provider during the execution of his activity [22]. Further applications of AR do exist in the construction industry [23], marketing [24], education [25] as well as healthcare [26, 27].

AR use cases in the context of more dynamic mobile settings, on the other hand, have been hardly the subject of research so far. These environments can be characterized by the fact that they are not limited in space and that objects - in contrast to those in static environments - do not necessarily have fixed positions, but the positions of these objects can change due to movements so that a motion emanates from the user's environment. One example is the process of driving a car, where the motion of other traffic participants influences the own process of driving, e.g., when it is necessary to brake because of the car in front brakes. For applications with relatively little or slow movement, head-mounted AR tools, such as HMDs, or other portable devices used for museum tours can be cited to provide audiovisual enhancements to support the tours [28, 29]. With regard to AR applications in the context of faster movements, the study by Berkemeier et al. [30], in which requirements for an acceptable smart glasses-based information system to support cyclists in cycling training are identified, can be mentioned. The aim of the study is to augment information such as speed or route details, which would otherwise have to be displayed by other devices, into the cyclist's field of view to promote road safety. There are also studies on cars in which head-up displays or head-mounted displays are used to display relevant information in the driver's field of view in order to reduce risks in road traffic [31] or to support driver safety training through simulated dangerous traffic situations [32].

Furthermore, in other safety-critical services, as it is the case in our use case, there are already some investigations on the support potential of AR and how it can be used. For example, the user requirements for an AR-based refinery training tool were determined for an oil refinery in order to develop usable and safe AR applications [33]. Another example is the application of AR in an innovative airport control power, where the aim was to provide the air traffic control operators in the airport control tower with complete head-up information [34, 35]. 
Theoretical accounts have developed concepts to capture how technologies affect service processes. A well-known theory is the process virtualization theory, which is concerned with explaining and predicting whether a process can be performed virtually [36]. Examples of virtualized processes include e-commerce, online distance learning, or online banking $[35,36]$. The theory has been applied and adapted in many different contexts, e.g. [35, 37], and was also examined with regard to augmentation, which led to the idea of the theory of process augmentability [38], that provides the basis for the analysis of the augmentability of our use case of the soil sounding service.

In contrast to the definition of virtualization, augmentation can be defined as the supplement of a synthetic or physical interaction. As a logical consequence, the four main constructs of the process virtualization theory concerning the potential removal of physical interactions from the process cannot be applied to augmentation. Therefore, one main construct - the authenticity requirement, which is based on the essentialist view of authenticity [39] and the authenticity framework of Grayson and Martinec [40] - is proposed to have a positive effect on the dependent variable, namely process augmentability. Process augmentability is described as "how amenable a process is to being conducted in AR environments" [38, p. 5].

Furthermore, three moderating constructs are proposed that are developed from the definition of AR, which is crucial to maintain a sense of hyper-reality [41]. By definition, AR must meet three criteria: combine physical and virtual, be interactive in real-time, and be registered in the real world [38, 42]. According to the definition, Yeo [38] proposed 3D visualization, spatial association, and synchronization as moderating constructs hereafter referred to as characteristics. The proposition of the 3D virtualization characteristic is informed by cognitive load theory [43]. For the characteristic of spatial association, examples were given in [38] of how AR uses the geospatial environments to enrich process experiences [20, 21, 26]. In terms of the synchronization characteristic, most physical processes conducted in the real world tend to be synchronous, and it is therefore important that the physical movement needs to be connected to maintain the sense of immersion [36].

\section{$3 \quad$ Methodology}

We conducted a case study [44] to explore the requirements for a user-centered AR solution for safety-critical services in the maritime sector. The use case we investigated was the process of soil sounding, i.e., water depth measurement in a harbor environment, which is carried out during navigation on a vessel.

In order to analyze how amenable the considered use case of the soil sounding process is to be supported by AR (RQ1), we first studied a promotional video of a European harbor operator that provided us with a contextual understanding of the soil sounding process as a foundation for the further analysis. In a second step, we collected data by conducting two semi-structured interviews and two workshops with business and IT experts of the same harbor operator (see table 1). Both the interviews and the workshops were documented by video recording. In addition, more detailed documents concerning the use case were provided by the participants, and additionally, notes were 
taken during the interview and workshop sessions. To get the first ideas of requirements for AR solutions for the service process of soil sounding (RQ2), we have briefly discussed them in the last part of the workshops with the experts. Since we wanted to identify user-centric requirements, we collected additional data with three skippers who actually perform the process of soil sounding.

\begin{tabular}{|c|c|c|c|c|}
\hline$\#$ & Source & Format & $\begin{array}{l}\text { Duration } \\
\text { (hh:mm) }\end{array}$ & Focus \\
\hline 1 & Harbor TV & Video & $00: 14$ & Use case context \\
\hline 2 & $\begin{array}{l}\text { Head of IT } \\
\text { Innovation }\end{array}$ & Interview & 01:00 & Overview case strategy \\
\hline 3 & $\begin{array}{l}\text { Deputy Port } \\
\text { Hydrographer }\end{array}$ & Interview & 01:00 & $\begin{array}{l}\text { Deeper understanding of the use } \\
\text { case context }\end{array}$ \\
\hline 4 & $\begin{array}{l}\text { Deputy Port } \\
\text { Hydrographer }\end{array}$ & Workshop & 02:03 & Requirements of the use case \\
\hline 5 & $\begin{array}{l}\text { Project Manager } \\
\text { R\&D }\end{array}$ & Workshop & $00: 57$ & $\begin{array}{l}\text { Process steps and requirements } \\
\text { of the use case }\end{array}$ \\
\hline 6 & Soil sounding 1 & Think Aloud & $01: 27$ & Soil sounding on a shore \\
\hline 7 & Soil sounding 2 & Think Aloud & 01:19 & $\begin{array}{l}\text { Soil sounding of harbor basin } \\
\text { and berths }\end{array}$ \\
\hline 8 & Soil sounding 3 & Think Aloud & 00:19 & $\begin{array}{l}\text { Follow-up soil sounding in a } \\
\text { relatively small area }\end{array}$ \\
\hline 9 & Soil sounding 4 & Think Aloud & $01: 16$ & $\begin{array}{l}\text { Soil sounding in a side arm with } \\
\text { several bridges and an open lock }\end{array}$ \\
\hline 10 & Soil sounding 5 & Think Aloud & $00: 28$ & $\begin{array}{l}\text { Soil sounding of a berth on a } \\
\text { quay }\end{array}$ \\
\hline 11 & Soil sounding 6 & Think Aloud & $00: 52$ & $\begin{array}{l}\text { Supplementary soil sounding of } \\
\text { a berth within a control } \\
\text { measurement }\end{array}$ \\
\hline 12 & Soil sounding 7 & Think Aloud & $00: 47$ & $\begin{array}{l}\text { Soil sounding of recently } \\
\text { dredged fields during heavy } \\
\text { traffic }\end{array}$ \\
\hline 13 & Soil sounding 8 & Think Aloud & 00:44 & Soil sounding of a dredging field \\
\hline 14 & Soil sounding 9 & Think Aloud & $00: 55$ & $\begin{array}{l}\text { Soil sounding of a widened } \\
\text { shipping channel }\end{array}$ \\
\hline 15 & Soil sounding 10 & Think Aloud & $00: 36$ & Soil sounding of a dredging field \\
\hline 16 & Soil sounding 11 & Think Aloud & $00: 12$ & $\begin{array}{l}\text { Soil sounding after removal of a } \\
\text { ground obstacle as control }\end{array}$ \\
\hline
\end{tabular}

Table 1. Data table of sources

In order to gain this central data source, we used the process tracing method [45] of thinking aloud [46], where the skippers were asked to "think aloud" and to explain everything they do while simultaneously engaging in the soil sounding service, in order to analyze which user-centered requirements an AR solution must meet to support the soil sounding process. As the situational features of the service are crucial, we extended 
the traditional implementation of the method by recording videos from different perspectives. For this purpose, we attached a camera to the skippers' forehead to retrace their field of view and another camera on the monitor to observe the skippers directly. An exact tracking of eye movements of the skippers was not necessary since only the direction of the skippers' view was relevant. With the help of the two recording perspectives and the recorded audio track, we were able to trace the process of soil sounding and derive user-centered requirements for an AR solution. As the service is critical to maintaining harbor operation, only experienced skippers are considered for soil sounding. The think-aloud sessions differ in the type of soil sounding job and its focus as well as the difficulty of the soil sounding, which depends on factors such as the soil sounding environment or traffic volume (see table 1).

For analyzing the video recordings and verbal protocols of the think-aloud sessions, we used the scanning method, which is one of the four major categories of protocol analysis and the most straightforward one [47]. We did not perform a verbatim transcription of what was said since the observation of the skippers was the primary object of investigation that we used for our analysis. Instead, the statements of the skippers helped to supplement and explain what was observed. For the identified video sequences in which observed behaviors indicated challenges, we transcribed what was said since this often helped to clarify and support the observation. We analyzed the video and audio material with three independent researchers and initially focused on existing challenges and problems in the process of soil sounding. After identifying all difficulties in the process, we derived problem categories by grouping duplicates and similar ones. Based on these problem categories, we finally derived the requirements described subsequently.

\section{Use Case of Water Depth Management in a Harbor Environment}

In the mobile use cases related to touring, cycling, and driving, two dimensions of motion occur: the motion of the user - which also occurs in static settings - and the motion of the environment. The ground on which the user moves can be described as static because it does not show any motion itself, such as a road. In the case of shipping, however, there is an additional dimension of motion, which is caused by the movement of the water on which the vessel is sailing, e.g., by currents or waves. While already the application of AR in cases with two dimensions of motion is difficult to implement, the application of AR on a vessel with this additional dimension of motion poses a particular challenge that needs to be investigated.

For our analysis, we chose the service process of water depth management in a European maritime logistics hub. Harbor personnel needs to continuously monitor water depth change due to sedimentation and erosion. In order to ensure the safety of vessel traffic and maintain the infrastructure, water depth management must be ensured by continuous soil sounding as well as finding and recognizing nautically critical obstacles on the water ground (e.g., bikes, cars, or shopping carts). Special soil 
sounding vessels are used that have the technical equipment to monitor water depth and generate a digital landscape model of the water ground live on board (see figure 1).
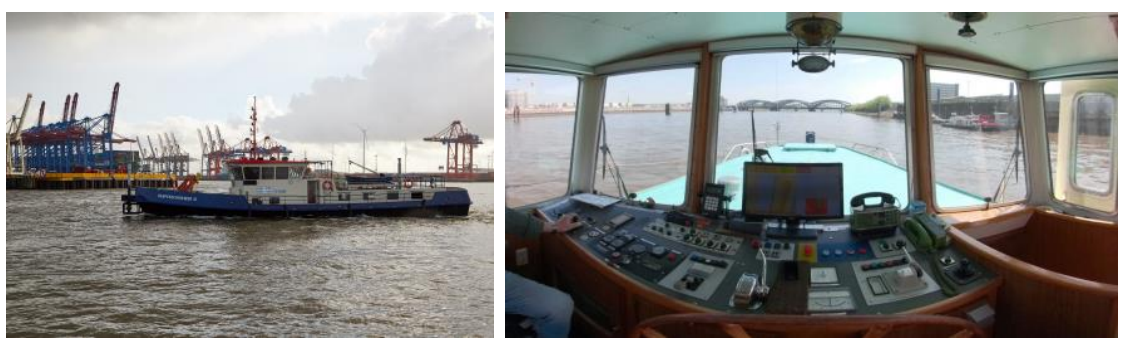

Figure 1. Exterior and interior view of a soil sounding vessel

Figure 2 illustrates the measurement depth management cycle to give an overview of the use case context. This states that the measurement of water depths generates knowledge, which in turn causes action, such as deepening a certain area. Since this action causes a change, the changing area must be controlled by measurement.

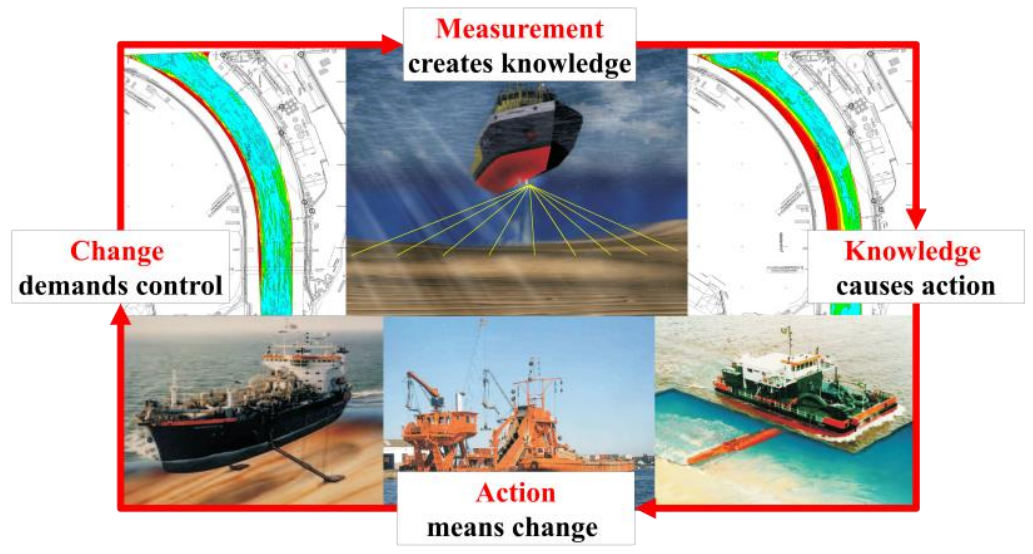

Figure 2. Measurement depth management cycle

The task of measuring water depth is particularly challenging: The skippers of soil sounding vessels use echo sounders to measure the water depths in the harbor while simultaneously paying attention to the vessel's traffic and keeping an eye on a variety of information for measurement on monitors so that they have to permanently switch between the monitors and the view out of the window. This leads to limited safety in vessel traffic, extreme exhaustion due to the constant change of view and context, and several health issues. These side effects of the constant shift of perspective can also be observed in other safety-critical services, such as the air traffic control in an airport control tower [34]. In addition to the simultaneous navigation of the vessel and measurement of data, the skipper needs to interact with a measurement engineer, who is accountable for controlling the quality of the measured data. The measurement engineer is either also on the vessel or works from the home office. 


\subsection{Augmentability of the Use Case}

Various attempts have already been made to solve the problem of the exhaustive and safety-critical shift in perspective between the view from the window onto the shipping traffic and the viewing of the data on the monitor. However, for example, the idea of placing the monitor in the windshield at the height of the skipper's eyes so that he no longer has to look down caused the monitor in the windshield to obscure important objects such as other vessels on the water. A further idea to reduce the size of the monitor in the windshield in order to avoid overlaying real objects has, in turn, resulted in the view of the displayed information and data being too small. Since it is important to display information in the skipper's field of view, but a monitor in the windscreen overlays important real objects, the application of AR seems to be a good way to solve the problem. With the help of AR, information can be displayed in the skipper's field of view without completely overlaying real objects. In order to investigate the applicability of AR for the use case, we have analyzed the use case with regard to the four characteristics that - according to the theory of process augmentability [38] - must be present in a process so that an augmentation of the process is appropriate.

Authenticity. The authenticity characteristic is present in the soil sounding service. The skipper requires an authentic experience to be supported in navigating his vessel and measuring data during the actual soil sounding process. This process cannot be virtualized or simulated due to its high complexity and dependence on the actions and decisions of the skipper. Accordingly, the process can only be performed in reality, and the information and support required by the skipper must correspond to this reality and extend it adequately.

3D visualization. The 3D visualization characteristic is present in the soil sounding process. The skipper requires 3D visualization for an authentic experience because a $2 \mathrm{D}$ visualization of obstacles and other ships is too imprecise, making it difficult to estimate sizes and distances, which in turn can affect the quality of the measurement data and traffic safety.

Spatial association. The spatial association characteristic is present in the soil sounding process. It is very important for the skipper that information, such as water depth and currents, as well as obstacles in the water and other vessels, are displayed with geographical accuracy. The skipper requires the possibility to obtain further information about, e.g., displayed objects through interaction with them. For example, if an obstacle or the water depth is not displayed geographically correct, and the skipper does not have access to important information, the vessel may collide with the obstacle or run aground.

Synchronization. The synchronization characteristic is present in the soil sounding process. The 3D objects to be augmented and the collected measurement data, as well as information about boundary conditions such as currents or the tide, must be continuously synchronized and updated, enabling the skipper to use this information to navigate his vessel safely and detect possible obstacles and measurement gaps or errors.

In summary, the soil sounding service is amenable to be supported by AR based on the analyzed characteristics and identified needs of the skipper involved in the process. 


\subsection{Requirements for AR Solutions}

Based on the challenges and problems that we have observed in the think-aloud sessions and subsequently analyzed, we identified five requirements for designing AR solutions for service processes such as soil sounding, which we specified together with the experts and skippers of the harbor operator. The identified requirements are (1) realtime overlay, (2) variety in displaying information, (3) multi-dimensional tracking, (4) collaboration, and (5) interaction.

Real-time overlay requirement. In all of the think-aloud sessions carried out, it was observed that during soil sounding, the skipper must be aware of a number of factors that may affect navigation and measurement, such as currents, the actual water level in the soil sounding area, in-water obstacles, general traffic and the data quality of the soil sounding. Since some information can only be acquired with the help of sensors and rapidly changing conditions prevail, the visualization of real-time information is an essential requirement to ensure that the skipper can navigate his vessel safely and, for example, is not in danger of running aground or hitting an obstacle.
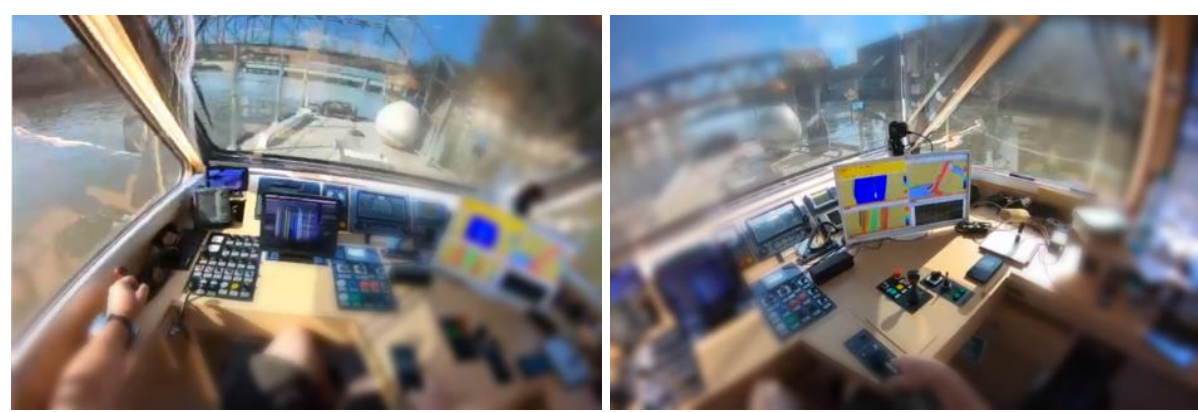

Figure 3. Example of the permanent view shift between the sailing window and monitor

During soil sounding on a shore in the first think aloud (soil sounding 1), the skipper explained: "If you like, I'll probably look $80 \%$ here on the monitor and maybe a little out the window". Therefore, a further challenge, which can impair traffic safety and even lead to health problems, is the constant shift of the skipper's attention between the sailing window to keep an eye on traffic and his monitors to ensure the quality of the measured data, as seen in figure 3. To meet this challenge, the elimination of media breaks by overlaying information directly into the user's field of view is required. For example, overlaying real-time information about other vessels, such as their position or direction of navigation, which is received via the Automatic Identification System (AIS) and currently displayed on different monitors, could help to ensure safety.

The real-time overlay requirement, therefore, arises from the need to display information in real-time and to overlay this display in the skipper's field of view in order to improve vessel traffic safety, prevent health issues, and reduce cognitive load. Additionally, such overlay can drastically improve safety during harsh weather conditions that reduce sight while dependence on digital information increases.

Variety in displaying information requirement. In addition to the frequent shifting of view between the vessel's window and the monitors (see figure 3), a variety of sensor information and data about the soil sounding area is displayed on different 
monitors, resulting in an additional constant shift between the monitors to ensure the quality of the measurement. Thereby the available space of the monitors is not optimally used, and sometimes even redundant information is displayed (see figure 4). However, in order to improve usability and thus enable the skipper to execute the measurement efficiently, the skipper requires certain multiple sensor information simultaneously, such as different layers or perspectives of the area of soil sounding, without information and the representation of this information being displayed several times.

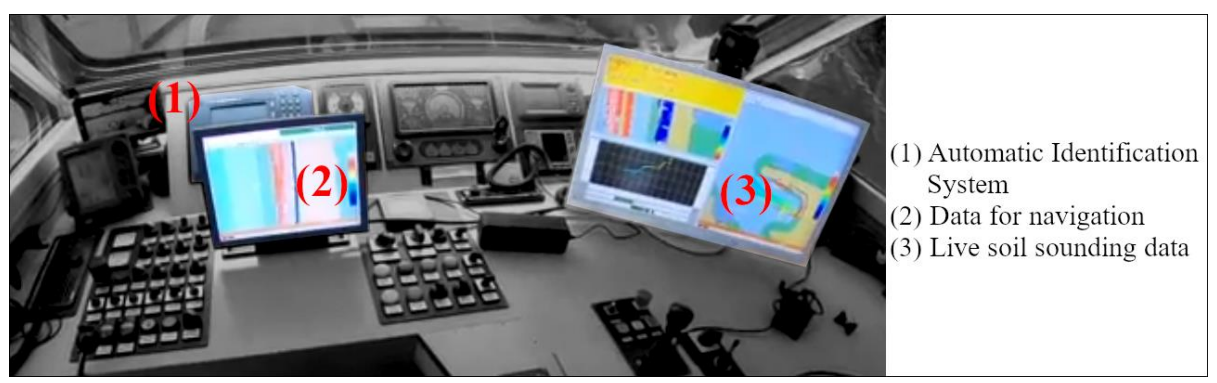

Figure 4. Variety of information and monitors on a soil sounding vessel

Another difficulty that also leads to the current use of multiple monitors is that information about the water level in general and the measured areas, which include the quality and density of the data, cannot be overlaid in the current IT system but are both required to ensure both traffic safety and measurement quality. Therefore, a further essential requirement regarding the presentation of information is that different views and representation options of the information should be distinguishable. In this context, we found out during the various think-aloud sessions that it is useful, for example, to have different zoom levels for the maps, since the skipper requires more detail to navigate his ship precisely, for instance, when measuring in narrow shore areas, than in wider water areas where he needs a greater overview. In several sessions, we could also observe that the skippers displayed the required information differently. In some measurement situations, for example, displaying the water depths in the measurement area using different color scales was more helpful than displaying this information as exact numerical values, and vice versa.

The variety in displaying information requirement, therefore, arises from the need to be able to choose different representation options of the information to display on demand in order to improve usability and traffic safety as well as ensuring the quality of the measurement.

Multi-dimensional tracking requirement. Compared to other means of transport such as bicycles or cars, a vessel has an additional dimension of motion since additional movements emanate from the ground, i.e., the water on which the vessel is sailing, making it even more difficult to track the vessel's exact position. However, it is an essential requirement for the navigation of the vessel during soil sounding to track the exact position of the vessel in relation to the environment. On the one hand, an inaccurate position determination can lead to measurement gaps and, accordingly, to a 
reduced measurement quality and, on the other hand, traffic safety can be impaired by incorrect positioning, since, for example, distances to obstacles or other vessels can no longer be displayed correctly.

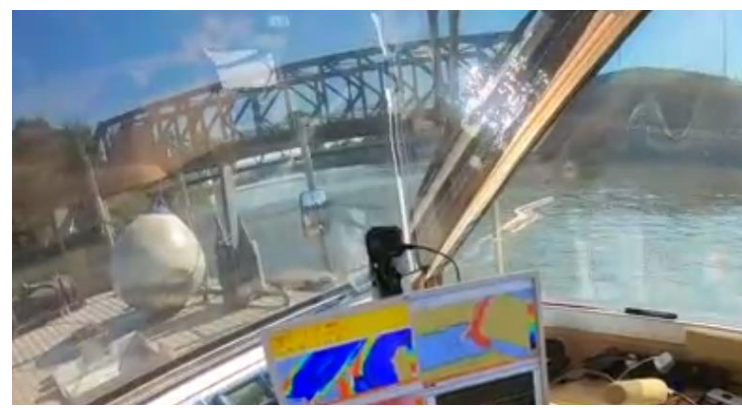

Figure 5. Direct sunlight and reflections

Tracking of the vessel's position is also made more difficult by the fact that the skipper is inside the ship and perceives the outside world through glass windows, making it difficult to avoid direct sunlight and reflections (see figure 5). Although the ships are equipped with sun protection roller shutters, which can attenuate the solar radiation, it is not possible to completely block the sun's rays without restricting the view outside too much by darkening it. Accordingly, the skipper requires tracking that is resistant to sunlight and reflections.

The multi-dimensional tracking requirement, therefore, arises from the fact that the skipper needs an exact positioning of the vessel in order to ensure traffic safety and the quality of the measurement data.

Collaboration requirement. During soil sounding, the skipper has to communicate a lot with other people to ensure traffic safety and quality of measurement. Both in terms of traffic safety and measurement, the skipper has to communicate with other vessels by radio in some situations. With regard to the quality of measurement, however, the collaboration with the measurement engineer, who is responsible for the technical implementation of the depth measurement, such as the configuration of the echo sounders, is most important. Before and during the measurement, the skipper and measurement engineer must continuously coordinate which areas are to be measured, how and when, and when the measuring devices must be activated or deactivated. They have to do this under consideration of different boundary conditions, e.g., the current water level. If the water level is too low, there is the risk of running aground, and if the water level is too high, it is, for example, no longer possible to pass every bridge. But above all, the constant communication about the observation of the live measured values and the flexible adaption of the course to them is of great importance since areas need to be measured again if the data quality is insufficient. A statement made by a skipper (think-aloud of soil sounding 7) summarizes very well the importance of the collaboration between him and the engineer during soil sounding: "If I don't synchronize with him [the measurement engineer], nothing will work".

To support collaboration, the skipper and the measurement engineer require the same visualization of the measuring areas, with additional highlighting of areas being useful because, especially when the measurement engineer is at the home office, it is not trivial 
to understand what about the other person is talking. It would also be useful to visualize whether the measurement device is activated and in which area it is currently collecting data. In addition, hands-free communication, i.e., without having to pick up a telephone, is required both with other vessels and with the measurement engineer, enabling the skipper to have his hands free for the navigation of the vessel and thus ensure safety.

The collaboration requirement, therefore, arises from the fact that the skipper has to communicate with other vessels and in particular, has to collaborate a lot with the measurement engineer in order to ensure both traffic safety and the quality of the measurement data.

Interaction requirement. The requirement of interaction goes along with the above-mentioned variety of displaying information requirement. Currently, information on the monitor cannot be manipulated by the skipper, or in other words, the skipper cannot interact with the system and is only able to consume information. During several think-aloud sessions, we observed that the skipper wanted to change the views on the monitor. Since the skipper is not able to interact with the system himself, he had to explain the necessary changes to the measurement engineer, who could then make the adjustments. It is therefore not possible for the skipper, for example, to show or hide information or to zoom into a map to get a detailed view if he requires it, e.g., to safely avoid obstacles or close measurement gaps. In order to carry out navigation and measurement more safely and efficiently, the skipper requires an appropriate opportunity to interact with the system.

The interaction requirement, therefore, arises from the fact that the skipper requires to show or hide important information or select detailed views to ensure traffic safety and completeness of the measurement data. Furthermore, the way of interaction should be chosen so that the skipper is not distracted from the navigation of the vessel.

\section{Discussion}

So far, little research on requirements for AR solutions has been done. Since the chosen use case is even more complex than the prior work on application areas of AR, we contribute to the state of research. Prior to investigating what requirements an AR solution must meet to support the service process of soil sounding, we examined the augmentability of the process using the theory of process augmentability [38]. We could determine that all four characteristics - which according to the theory, must be present in a process - are existent in the process of soil sounding so that an augmentation of the process is sensible and could help to facilitate and improve the process. This result is consistent with the taxonomy study by Klinker et al. [48], who investigated for which processes in logistics an AR application is appropriate. As the process of soil sounding is a difficult case from practice, and therefore laboratory conditions are not given, implementing an AR solution is a big challenge, but it should be tackled to support practice.

In sum, we derived five core requirements from the case of soil sounding for the application of AR, namely (1) real-time overlay, (2) variety in displaying information, (3) multi-dimensional tracking, (4) collaboration, and (5) interaction. In addition, three 
general underlying requirements emerge related to traffic safety, health, and usability, which are included in all five requirement areas. Compared to the requirements for smart glasses-based AR systems for cycling training [30] and to the use of AR in driving situations [31,32], there are some similarities because in all these cases, an AR solution has to be applied in a mobile environment and the users act in a traffic situation. Both a failure in road traffic and one in the navigation of a vessel in shipping traffic can have serious consequences. In contrast to cycling or driving a car, however, our use case takes place in an environment where there is a further dimension of motion and consequently more degrees of freedom. Therefore, the multi-dimensional tracking requirement poses an even greater challenge to existing AR hardware as it is in the case of road traffic. Especially for soil soundings, where the measurement had to be carried out in a narrow area or where there was a high volume of traffic, exact tracking is essential. This applies not only to soil sounding vessels but to all other types of vessels as well, whereby the failure tolerance decreases as vessels approach narrow or restricted fairways and increasing traffic density [49]. Furthermore, the use case of soil sounding gains in complexity since the user has to perform another task in addition to navigating the vessel, namely the service task of depth measurement in order to ensure harbor infrastructure and thus traffic safety. Moreover, from a methodological point of view, our approach contributes to new standards of research. By underpinning the thinking aloud method with video material from various perspectives, we were able to gain the best possible understanding of the spatial implications and requirements for AR. Thereby the enriched thinking aloud material helps to gain further insights and learnings about the user-centered requirements. Additionally, our approach is beneficial in environments that do not meet the standards of typical scientific interviews by being noisy, weather-dependent, and dirty.

However, our approach is not entirely free of limitations. Since we have only focused on one specific use case, that of soil sounding in water depth management, our results are contextual. Nevertheless, we assume a transferability to other use cases. For this purpose, further use cases in the maritime logistics environment could be considered. One possible case is the dredging industry, which is responsible for adjusting and dredging the water depths. Furthermore, use cases in the field of pilotage in the harbor could be considered. Moreover, a floating drone is used for water depth management and soil sounding. Also, in this case, potentials are recognizable, since with the help of $\mathrm{AR}$, for example, the drone operator could take a first-person view in addition to a thirdperson view regarding the drone.

\section{Conclusion}

In summary, we have shown that the soil sounding service is augmentable in general. Knowing the augmentation potential, we derived five user-centered requirements for the soil sounding process, using the results of the thinking aloud sessions as a foundation: (1) real-time overlay, (2) variety in displaying information, (3) multidimensional tracking, (4) collaboration, and (5) interaction requirement. The requirements for an AR solution, which we have determined with regard to the 
navigation task of the skipper, correspond to the results of previous research on AR applications in road traffic. However, never before has such a complex process as that of soil sounding been investigated, so we are contributing to the research at this point. On the one hand, the moving vessel in combination with the moving user inside the vessel poses a great challenge in terms of multidimensional tracking possibilities. On the other hand, it is a knowledge-intense process that requires multitasking, i.e. a constant shift between the navigation of the vessel and the measurement of water depth, and collaboration with the measurement engineer. Furthermore, the process is subject to enormous safety critical requirements, which must be considered additionally.

Besides the above-mentioned tracking, future challenges will be to determine whether supporting the process with AR is beneficial for the skipper from a user perspective and, if so, in what form AR can be used to achieve the greatest possible advantage. For this purpose, a prototypical implementation and evaluation will be initiated in the future to explore the subjective usefulness of AR in the soil sounding context. In this context the requirements should be evaluated more detailed with experts from the maritime industry as well as AR solution developers regarding their technical feasibility, whereby the focus should be on interfaces, data types and data quality. Not least, the transferability to other use cases, e.g. in the harbor environment and general industrial as well as logistic scenarios, remains to be investigated.

\section{Acknowledgements}

This research was partly sponsored by the German Federal Ministry for Education and Research and in the project WizARd under the reference 02K18D180 and 02K18D181. Further information can be found under: http://www.wizard.tu-dortmund.de/.

\section{References}

1. Ostrom, A.L., Parasuraman, A., Bowen, D.E., Patrício, L., Voss, C.A.: Service Research Priorities in a Rapidly Changing Context. Journal of Service Research 18, 127-159 (2015)

2. Wirtz, J., Patterson, P.G., Kunz, W.H., Gruber, T., Lu, V.N., Paluch, S., Martins, A.: Brave new world: service robots in the frontline. Journal of Service Management 29, 907-931 (2018)

3. Jeffers, P.I., Muhanna, W.A., Nault, B.R.: Information Technology and Process Performance: An Empirical Investigation of the Interaction Between IT and NonIT Resources. Decision Sciences 39, 703-735 (2008)

4. Collier, D.A.: The service/quality solution: Using service management to gain competitive advantage. Irwin Professional Publishing, Milwaukee, WI (1994)

5. Haksever, C., Render, B., Russell, R.S., Murdick, R.G.: Service management and operations. Prentice-Hall, Upper Saddle River, NJ (2000)

6. Böhmann, T., Leimeister, J.M., Möslein, K.: Service systems engineering. Business \& Information Systems Engineering 6, 73-79 (2014) 
7. Niemöller, C., Metzger, D., Berkemeier, L., Zobel, B., Thomas, O.: Mobile Service Support based on Smart Glasses. Journal of Information Technology Theory and Application 20, 77-108 (2019)

8. Niemöller, C., Metzger, D., Thomas, O.: Design and evaluation of a smartglasses-based service support system. In: Proceedings of the 13th International Conference on Wirtschaftsinformatik, pp. 106-120 (2017)

9. Elder, S., Vakaloudis, A.: Towards uniformity for smart glasses devices: An assessment of function as the driver for standardisation. In: 2015 IEEE International Symposium on Technology and Society (ISTAS), pp. 1-7. IEEE, Piscataway, NJ (2015)

10. Metzger, D., Niemöller, C., Thomas, O.: Design and demonstration of an engineering method for service support systems. Information Systems and eBusiness Management 15, 789-823 (2017)

11. Klinker, K., Fries, V., Wiesche, M., Krcmar, H.: CatCare: Designing a serious game to foster hand hygiene compliance in health care facilities. In: Proceedings of the 12th International Conference on Design Science Research in Information Systems and Technology (DESRIST), pp. 20-28. Karlsruher Institut für Technologie (KIT) (2017)

12. Niemöller, C., Zobel, B., Berkemeier, L., Metzger, D., Werning, S., Adelmeyer, T., Ickerott, I., Thomas, O.: Sind Smart Glasses die Zukunft der Digitalisierung von Arbeitsprozessen? Explorative Fallstudien zukünftiger Einsatzszenarien in der Logistik. In: Proceedings of the 13th International Conference on Wirtschaftsinformatik, pp. 410-424 (2017)

13. Rauschnabel, P.A., Ro, Y.K.: Augmented reality smart glasses: An investigation of technology acceptance drivers. International Journal of Technology Marketing 11, 123-148 (2016)

14. Knight, J.C.: Safety critical systems. In: Tracz, W., Magee, J., Young, M. (eds.) Proceedings of the 24th international conference on Software engineering - ICSE '02, pp. 547-550. ACM Press, New York, New York, USA (2002)

15. Lusch, R.F., Nambisan, S.: Service Innovation: A Service-Dominant Logic Perspective. MISQ 39, 155-175 (2015)

16. Jessen, A., Hilken, T., Chylinski, M., Mahr, D., Heller, J., Keeling, D.I., Ruyter, K. de: The playground effect: How augmented reality drives creative customer engagement. Journal of Business Research 116, 85-98 (2020)

17. Matijacic, M., Fellmann, M., Özcan, D., Kammler, F., Nüttgens, M., Thomas, O.: Elicitation and consolidation of requirements for mobile technical customer services support systems-a multi-method approach. In: Proceedings of the 34th International Conference on Information Systems (ICIS) (2013)

18. Thomas, P.C., David, W.M.: Augmented reality: An application of heads-up display technology to manual manufacturing processes. In: Proceedings of the 25th Hawaii International Conference on System Sciences (HICCS), pp. 659-669 (1992)

19. Huck-Fries, V., Wiegand, F., Klinker, K., Wiesche, M., Krcmar, H.: Datenbrillen in der Wartung. In: Eibl, M., Gaedke, M. (ed.) INFORMATIK 2017, pp. 14131424. Gesellschaft für Informatik, Bonn (2017) 
20. Henderson, S., Feiner, S.: Exploring the benefits of augmented reality documentation for maintenance and repair. IEEE transactions on visualization and computer graphics 17, 1355-1368 (2011)

21. Sandor, C., Klinker, G.: A rapid prototyping software infrastructure for user interfaces in ubiquitous augmented reality. Personal and Ubiquitous Computing 9, 169-185 (2005)

22. Metzger, D., Niemöller, C., Berkemeier, L., Brenning, L., Thomas, O.: Vom Techniker zum Modellierer - Konzeption und Entwicklung eines Smart Glasses Systems zur Laufzeitmodellierung von Dienstleistungsprozessen. In: Thomas, O., Nüttgens, M., Fellmann, M. (eds.) Smart Service Engineering. Konzepte und Anwendungsszenarien für die digitale Transformation, pp. 193-213. Springer Gabler, Wiesbaden (2017)

23. Dunston, P.S., Wang, X.: Mixed Reality-Based Visualization Interfaces for Architecture, Engineering, and Construction Industry. Journal of Construction Engineering and Management 131, 1301-1309 (2005)

24. Yaoyuneyong, G., Foster, J., Johnson, E., Johnson, D.: Augmented Reality Marketing: Consumer Preferences and Attitudes Toward Hypermedia Print Ads. Journal of Interactive Advertising 16, 16-30 (2016)

25. Kaufmann, H., Schmalstieg, D.: Mathematics and geometry education with collaborative augmented reality. Computers \& Graphics 27, 339-345 (2003)

26. Sielhorst, T., Feuerstein, M., Navab, N.: Advanced Medical Displays: A Literature Review of Augmented Reality. Journal of Display Technology 4, 451467 (2008)

27. Klinker, K., Wiesche, M., Krcmar, H.: Digital Transformation in Health Care: Augmented Reality for Hands-Free Service Innovation. Information Systems Frontiers 22, 1419-1431 (2020)

28. Sparacino, F.: The Museum Wearable: Real-Time Sensor-Driven Understanding of Visitors' Interests for Personalized Visually-Augmented Museum Experiences (2002)

29. Miyashita, T., Meier, P., Tachikawa, T., Orlic, S., Eble, T., Scholz, V., Gapel, A., Gerl, O., Arnaudov, S., Lieberknecht, S.: An Augmented Reality museum guide. In: Proceedings of the 7th IEEE/ACM International Symposium on Mixed and Augmented Reality, pp. 103-106 (2008)

30. Berkemeier, L., Menzel, L., Remark, F., Thomas, O.: Acceptance by design: towards an acceptable smart glasses-based information system based on the example of cycling training. In: Multikonferenz Wirtschaftsinformatik (MKWI) (2018)

31. Heymann, M., Degani, A.: Classification and organization of information. In: Shaked, N., Winter, U. (eds.) Design of Multimodal Mobile Interfaces, pp. 195217 (2016)

32. Regenbrecht, H., Baratoff, G., Wilke, W.: Augmented reality projects in the automotive and aerospace industries. IEEE Computer Graphics and Applications 25, 48-56 (2005)

33. Träskbäack, M., Haller, M.: Mixed reality training application for an oil refinery: user requirements. In: Proceedings of the 2004 ACM SIGGRAPH International 
Conference on Virtual Reality Continuum and its Applications in Industry, pp. 324-327 (2004)

34. Bagassi, S., Crescenzio, F. de, Piastra, S., Persiani, C.A., Ellejmi, M., Groskreutz, A.R., Higuera, J.: Human-in-the-loop evaluation of an augmented reality based interface for the airport control tower. Computers in Industry 123, 103291 (2020)

35. Balci, B., Rosenkranz, C.: "Virtual or material, what do you prefer?" A study of process virtualization theory. In: Proceedings of the 22nd European Conference on Information System (ECIS) (2014)

36. Overby, E.: Process Virtualization Theory and the Impact of Information Technology. Organization science 19, 277-291 (2008)

37. Bose, R., Luo, X.: Integrative framework for assessing firms' potential to undertake Green IT initiatives via virtualization - A theoretical perspective. The Journal of Strategic Information Systems 20, 38-54 (2011)

38. Yeo, J.: The Theory of Process Augmentability. In: Proceedings of the 38th International Conference on Information Systems (ICIS) (2017)

39. Newman, G.E.: An Essentialist Account of Authenticity. Journal of Cognition and Culture 16, 294-321 (2016)

40. Grayson, K., Martinec, R.: Consumer Perceptions of Iconicity and Indexicality and Their Influence on Assessments of Authentic Market Offerings. Journal of Consumer Research 31, 296-312 (2004)

41. Baudrillard, J.: Simulations. Translated by Paul Foss, Paul Patton and Philip Beitchman. Semiotext (E), New York (1983)

42. Azuma, R.T.: A Survey of Augmented Reality. Presence: Teleoperators and Virtual Environments 6, 355-385 (1997)

43. Huang, W., Eades, P., Hong, S.-H.: Measuring Effectiveness of Graph Visualizations: A Cognitive Load Perspective. Information Visualization 8, 139152 (2009)

44. Yin, R.K.: Case study research: Design and methods. Thousand Oaks, CA: Sage (2003)

45. Todd, P., Benbasat, I.: Process Tracing Methods in Decision Support Systems Research: Exploring the Black Box. MISQ 11, 493 (1987)

46. van Someren, M.W., Barnard, Y.F., Sandberg, J.A.C.: The think aloud method: a practical approach to modelling cognitive. Academic Press, London (1994)

47. Bouwman, M.J.: Human Diagnostic Reasoning by Computer: An Illustration from Financial Analysis. Management Science 29, 653-672 (1983)

48. Klinker, K., Berkemeier, L., Zobel, B., Wüller, H., Huck-Fries, V., Wiesche, M., Remmers, H., Thomas, O., Krcmar, H.: Structure for innovations: A use case taxonomy for smart glasses in service processes. In: Multikonferenz Wirtschaftsinformatik (MKWI) (2018)

49. Gardenier, J.S.: Ship navigational failure detection and diagnosis. In: Human detection and diagnosis of system failures, pp. 49-74. Springer (1981) 